\title{
Incidence and clinical impact of vertebral endplate changes after limited lumbar microdiscectomy and implantation of a bone-anchored annular closure device
}

\author{
Jenny C. Kienzler ${ }^{1 *}\left(\mathbb{1}\right.$, Sofia Rey ${ }^{1,2,3}$, Oliver Wetzel ${ }^{1}$, Hermien Atassi ${ }^{3}$, Sabrina Bäbler ${ }^{1}$, Felice Burn ${ }^{1}$
} and Javier Fandino ${ }^{1}$

\begin{abstract}
Background: An annular closure device (ACD) could potentially prevent recurrent herniation by blocking larger annular defects after limited microdiscectomy (LMD). The purpose of this study was to analyze the incidence of endplate changes (EPC) and outcome after LMD with additional implantation of an ACD to prevent reherniation.

Methods: This analysis includes data from a) RCT study-arm of patients undergoing LMD with ACD implantation and b) additional patients undergoing ACD implantation at our institution. Clinical findings (VAS, ODI), radiological outcome (reherniation, implant integrity, volume of EPC) and risk factors for EPC were assessed.

Results: Seventy-two patients (37 men, 47 \pm 11.63yo) underwent LMD and ACD implantation between 2013-2016. A total of 71 (99\%) patients presented with some degree of EPC during the follow-up period (14.67 4.77 months). In the multivariate regression analysis, localization of the anchor was the only significant predictor of EPC $(p=0.038)$. The largest EPC measured $4.2 \mathrm{~cm}^{3}$. Reherniation was documented in 17 (24\%) patients (symptomatic: $n=10$; asymptomatic: $n=7)$. Six (8.3\%) patients with symptomatic reherniation underwent rediscectomy. Implant failure was documented in 19 (26.4\%) patients including anchor head breakage $(n=1,1.3 \%)$, dislocation of the whole device $(n=5$, $6.9 \%)$, and mesh dislocation into the spinal canal $(n=13,18 \%)$. Mesh subsidence within the EPC was documented in 15 (20.8\%) patients. Seven (9.7\%) patients underwent explantation of the entire, or parts of the device.
\end{abstract}

Conclusion: Clinical improvement after LMD and ACD implantation was proven in our study. High incidence and volume of EPC did not correlate with clinical outcome. The ACD might prevent disc reherniation despite implant failure rates. Mechanical friction of the polymer mesh with the endplate is most likely the cause of EPC after ACD.

Keywords: Disc herniation, Reherniation, Endplate changes, Annular closure device, Polymer mesh, Barricaid ${ }^{\circledR}$

\section{Background}

Limited lumbar microsurgical discectomy (LMD) to remove the free disc fragment is the gold standard treatment for patients with refractory disc herniation

\footnotetext{
*Correspondence: jenny.kienzler@ksa.ch

1 Department of Neurosurgery, Kantonsspital Aarau, Tellstrasse,

5001 Aarau, Switzerland

Full list of author information is available at the end of the article
}

related radicular pain [22]. However, the failure rate of discectomy is high due to recurrent disc herniation, progression of degenerative disc disease (DDD) and continuing chronic low back pain [16]. The rate of recurrent herniation is $3 \%-18 \%$ in limited discectomy and correlates among other predictive factors with the annular defect area and percentage of removed disc material [24]. A defect size of $>6 \mathrm{~mm}$ wide has a 
reherniation rate of 27\% [6]. Aggressive discectomy on the other hand, may lead to accelerated DDD, instability and disc height collapse with chronic low back pain [24]. Symptomatic recurrent herniation management is either conservative or with repeat surgery including discectomy or fusion [18]. The outcome after repeat surgery is often inferior to primary surgery [9]. An annular closure device (ACD) (Barricaid $^{\circledR}$, Intrinsic Therapeutics, Inc., Woburn, MA) was recently introduced and could potentially prevent recurrent herniation by blocking larger annular defects after LMD, and preserve the nucleus pulposus within the disc space [19]. The results of a European multicenter randomized controlled trial (RCT) with 550 patients have recently been published. It was shown that the frequency of symptomatic reherniation and reoperation was lower in the ACD compared to the control group-with a similar outcome over a 3-year period [12, 23]. Endplate changes (EPC), however, were more prevalent in the ACD group (84\% vs. 30\%) [23]. Further post hoc analysis investigating the occurrence of EPC identified mechanical stress from the ACD on the endplates as cause of the significant increase of EPC [5]. There was no correlation with outcome (low back pain or ODI) [5, 14]. The aim of the present study is to share our institution's experience with EPC following LMD with additional implantation of an ACD.

\section{Methods}

\section{Study design}

This analysis includes data from (a) European multicenter RCT study-arm of patients undergoing LMD with implantation of the ACD Barricaid ${ }^{\circledR}$ and (b) additional patients undergoing implantation of commercially available ACD at our institution. Lumbar disc herniation patients scheduled for LMD with a posterior disc height of at least $5 \mathrm{~mm}$ were offered ACD implantation. Further information on the RCT study protocol including inclusion and exclusion criteria can be found in the main study publication [23]. Informed consent was obtained for all RCT patients. Prior ethics committee approval was obtained for the multicenter randomized study and for the retrospective data analysis (EC numbers 2012/036; 2016/01740). This study is in accordance with the STROBE guidelines. The results from our study have been previously presented at the AANS conference 2019 [11].

\section{Outcome measures}

$\mathrm{X}$-ray, computed tomography $(\mathrm{CT})$ and magnetic resonance imaging (MRI) was performed prior and at the one year follow up. Clinical outcome assessment included pre- and postoperative score assessment of Visual Analogue Scale (VAS) [10], and Oswestry Disability Index (ODI) [7].

\section{Volumetry of osteolytic endplate changes}

Endplate changes (EPC) were classified as any new erosion of subchondral bone, vertebral or cartilaginous endplate. Location of EPC (lower or upper endplate) and the relation of the titanium device anchor (superior or inferior endplate) to the vertebra were determined (Fig. 1). Measurements of EPC volume $\left(\mathrm{cm}^{3}\right)$ in the lumbar spine $\mathrm{CT}$ were performed using a commercially available software (Elements ${ }^{\circledR}$, Brainlab, Munich, Germany) (Fig. 2). To increase reliability, all measurements were performed by two neurosurgeons. The interobserver agreement results were accepted for final analysis.

\section{Endplate and disc degeneration}

All EPC were additionally classified according to Modic criteria [17] and DDD was assessed by applying Pfirrmann classification [20]. An independent neuroradiologist conducted all measurements. Disc height was assessed in the pre- and postoperative MRI within $5 \mathrm{~mm}$ of the posterior border. In order to rule out measurement errors, 50 randomly selected cases were reevaluated by the first author.

\section{EPC grading system}

We aimed to establish a descriptive grading classification of EPC ranging from 1 to 4 to better assess the extent of EPC and simplify radiological description. The EPC classification includes 2 criteria: localization of device anchor in the vertebra (superior or inferior) and EPC volume $\left(<1 \mathrm{~cm}^{3}\right.$ or $\left.>1 \mathrm{~cm}^{3}\right)$.

\section{Statistical methods}

A multivariate regression model was developed in which a linear combination of EPC was regressed on all potential predictive factors to define their significance. Univariate analysis was performed to examine the effect of defined risk factors on the location of EPC (upper vs. lower). The clinical influence of EPC on pain (VAS) and disability scores (ODI) were investigated with a univariate regression analysis of EPC and each outcome parameter. A paired t-test was performed to compare normally distributed continuous data and Wilcoxon rank sum test for non-parametric data. 

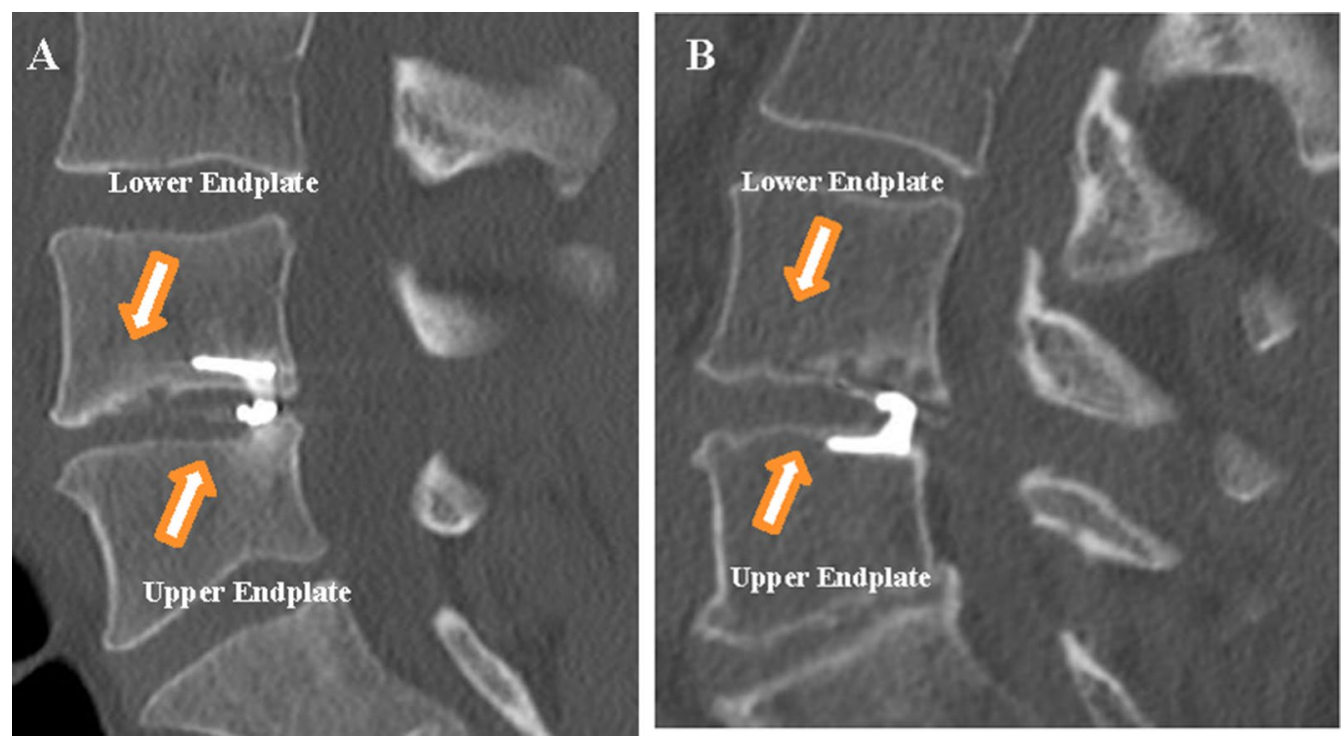

Fig. 1 Demonstration of the nomenclature of upper and lower endplate changes in relation to the vertebra. a ACD anchor implanted in the inferior endplate of $L 4$ with EPC in the upper endplate of $L 5$. b ACD anchor in the superior endplate of $L 5$ with EPC in the lower EP of $L 4$. EPC Endplate changes, EP Endplate

\section{Results}

\section{Patient characteristics}

A total of 72 patients (37 men) underwent LMD and ACD implantation between January 2013 and October 2016 at a single institution. Twenty-nine patients had surgery and ACD implantation within the randomized controlled trial and 43 were "commercial cases". The median age at time of surgery was $47 \pm 11.63$ years. Overall median follow-up was $14.67 \pm 4.77$ months. Forty-six patients (64\%) had smoked at some point in their lives; 33 (46\%) of them were still active smokers and 14 (19\%) had quit the habit. Forty-seven (67\%) patients had a job requiring heavy lifting. The remaining 25 (33\%) had an occupation with lighter physical demands and 5 (20\%) were already retired.

\section{Intraoperative Parameters initial surgery}

There were no surgical complications. The mean annular defect size was $7.77 \pm 1.27 \mathrm{~mm}$ in width and $1.35 \pm 0.77 \mathrm{cc}$ of disc material was removed on average. The difficulty of surgical procedure with respect to ACD implantation was generally rated as easy or acceptable.

\section{Endplate changes}

Endplate changes were found in 71 (99\%) patients included in this study. These EPC volumes were significantly larger in the lower endplate (EP) of the vertebra, with a median of $230 \mathrm{~mm}^{3}$, compared with those in the upper EP, with a median of $105 \mathrm{~mm}^{3}(\mathrm{p}=0.006)$ (Fig. 3). The largest EPC was $4.2 \mathrm{~cm}^{3}$. A multivariate regression analysis of risk factors for development of EPC at the upper or lower endplate only produced one significant predictor: the ACD anchor localization $(\mathrm{p}=0.038)$ (Table 1). Subsequent univariate regression analysis showed that multivariate contribution of anchor localization is based on a significant effect of lower EPC after anchor implantation in the superior EP $(\mathrm{p}=0.025)$ (Table 2). In the current study group, 46 (64\%) ACD titanium anchors were implanted in the superior EP with the polymer mesh linked to the lower EP of the adjacent vertebra. We analyzed median upper and lower EPC volumes in association to anchor localization (Fig. 4). A significant difference between the inferior and superior anchor localization was only present at the lower EP $(\mathrm{p}=0.022)$.

\section{Descriptive score}

This grading system was based on the fact that patients with ACD in inferior endplate had, on average, smaller EPC compared to superior EP fixation. Table 3 presents the descriptive criteria for the ACD-EPC scoring system. The scoring system was validated in our patient cohort and Table 4 presents the distribution in our study cohort.

\section{Case report}

Figure 5 illustrates a case of a 52 year-old women who underwent LMD and ACD implantation at L4/5 level due to disc herniation and persistent L5 radicular pain. Preoperative CT confirmed absence of any EPC. LMD and ACD implantation in the superior EP of L5 

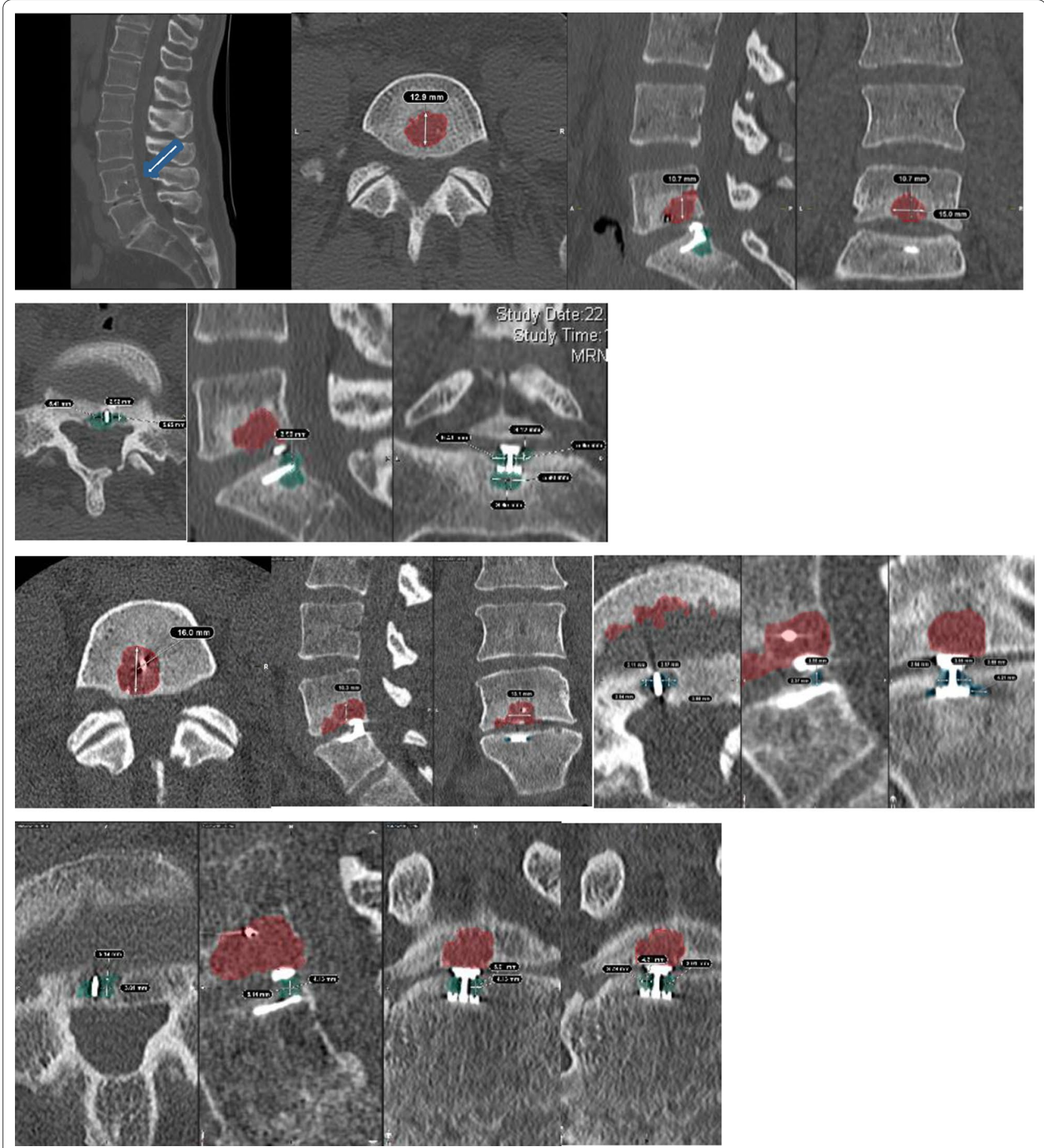

Fig. 2 Multiple examples of patients with EPC and the volume measurement technique using Elements software (Brainlab ${ }^{\circledR}$, Munich, Germany)

was successful, no complications occurred intraoperative and radicular pain was resolved postoperatively. At one-year follow-up, EPC (size $\left.=0.57 \mathrm{~cm}^{3}\right)$ had appeared around the mesh at the lower EP of L4. Only minimal changes were noticeable below the titanium anchor at upper EP of L5. After 2 years, EPC $\left(\right.$ size $\left.=1.15 \mathrm{~cm}^{3}\right)$ progressed in the lower EP of L4 and at the 3 years follow-up, EPC $\left(2.46 \mathrm{~cm}^{3}\right)$ increased to a grade 3, with polymer mesh subsidence into the lower EP of L4. Instability caused increasing facet joint-associated low 


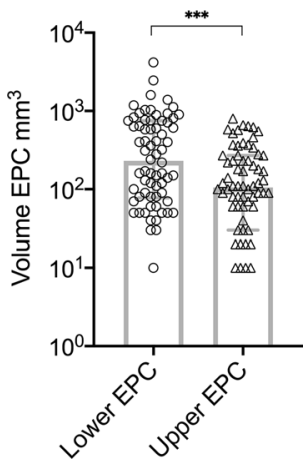

Fig. 3 Median EPC volume with interquartile range (25\%-75\% quartiles) of all patients at the lower and upper endplate, $\log (10)$ scale. $p=0.006$

Table 1 Results of the multivariate regression analysis of risk factors for EPC of the lower and upper endplate revealed only one significant parameter: anchor localization in superior endplate

\begin{tabular}{ll}
\hline Multivariate regression analysis & p-value \\
\hline Sex (effect of male) & 0.4502 \\
Smoker & 0.1487 \\
Age & 0.6961 \\
Anchor localization (superior) & 0.0380 \\
Heavy lifting & 0.2494 \\
Amount of disc material removed & 0.8110 \\
Size of defect & 0.5105 \\
Preoperative disc height & 0.6468 \\
Postoperative Pfirrmann score & 0.8367 \\
Postoperative Modic score & 0.7446
\end{tabular}

$E P C$ endplate changes

Table 2 Univariate regression analysis and significance level of each predictor on lower EPC

\begin{tabular}{ll}
\hline Univariate regression analysis & p-value \\
\hline Sex (effect of male) & 0.9182 \\
Smoker & 0.4776 \\
Age & 0.4337 \\
Anchor localization (superior) & 0.0252 \\
Heavy lifting & 0.1245 \\
Amount of disc material removed & 0.6441 \\
Size of defect & 0.2446 \\
Preoperative disc height & 0.8333 \\
Postoperative Pfirrmann score & 0.5502 \\
Postoperative Modic score & 0.8817 \\
\hline
\end{tabular}

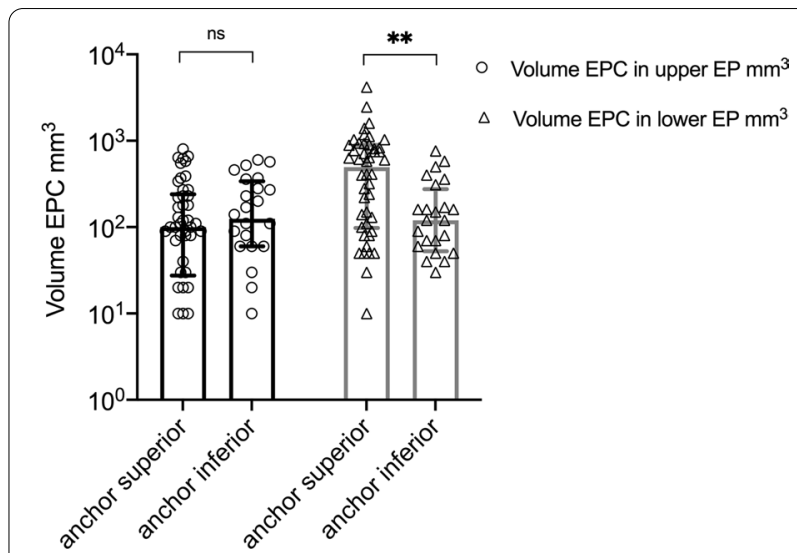

Fig. 4 Median lower and upper EPC volumes with interquartile range (25\% - $75 \%$ quartiles), split out for the two anchor locations superior and inferior, $\log (10)$ scale. $p=0.002$

Table 3 Introduction of a new classification of ACD associated EPC. The EPC score ranges from 1 to 4 and assesses anchor localization (superior/inferior) and size of EPC $\left(<1 \mathrm{~cm}^{3} />1 \mathrm{~cm}^{3}\right)$ as criteria. Scores were defined as follows: grade 1 includes patients with ACD implanted on inferior EP and EPCs of $<1 \mathrm{~cm}^{3}$, grade 2 have an ACD in the superior EP and EPCs $<1 \mathrm{~cm}^{3}$, grade 3 received $A C D$ in inferior $E P$ and $E P C s>1 \mathrm{~cm}^{3}$, and finally maximum grade 4 if $A C D$ is in the superior EP and the EPCs are $>1 \mathrm{~cm}^{3} \cdot \mathrm{ACD}=$ Annular closure device

\begin{tabular}{clc}
\hline & $\begin{array}{l}\text { Localization } \\
\text { of the anchor }\end{array}$ & Size of the EPC \\
\hline EPC classification & & \\
Grade 1 & Caudal & $<1 \mathrm{~cm}^{3}$ \\
Grade 2 & Cranial & $<1 \mathrm{~cm}^{3}$ \\
Grade 3 & Caudal & $>1 \mathrm{~cm}^{3}$ \\
Grade 4 & Cranial & $>1 \mathrm{~cm}^{3}$ \\
\hline
\end{tabular}

Table 4 Validation of the EPC classification in our study cohort. A maximum achievable score of 4 points corresponds to severe EPC and the minimum of one point indicates mild EPC. Scores of 2 to 3 points are considered intermediate

\begin{tabular}{rrrr}
\hline I & II & III & IV \\
\hline EPC grading in our cohort & & \\
23 & 40 & 0 & 8 \\
\hline
\end{tabular}

back pain and the patient underwent subsequent fusion and removal of the implant.

Reoperation due to reherniation or device failure At the time of study analysis in 2018, 65 patients (90\%) were still living with the implant and in $7(10 \%)$ patients 

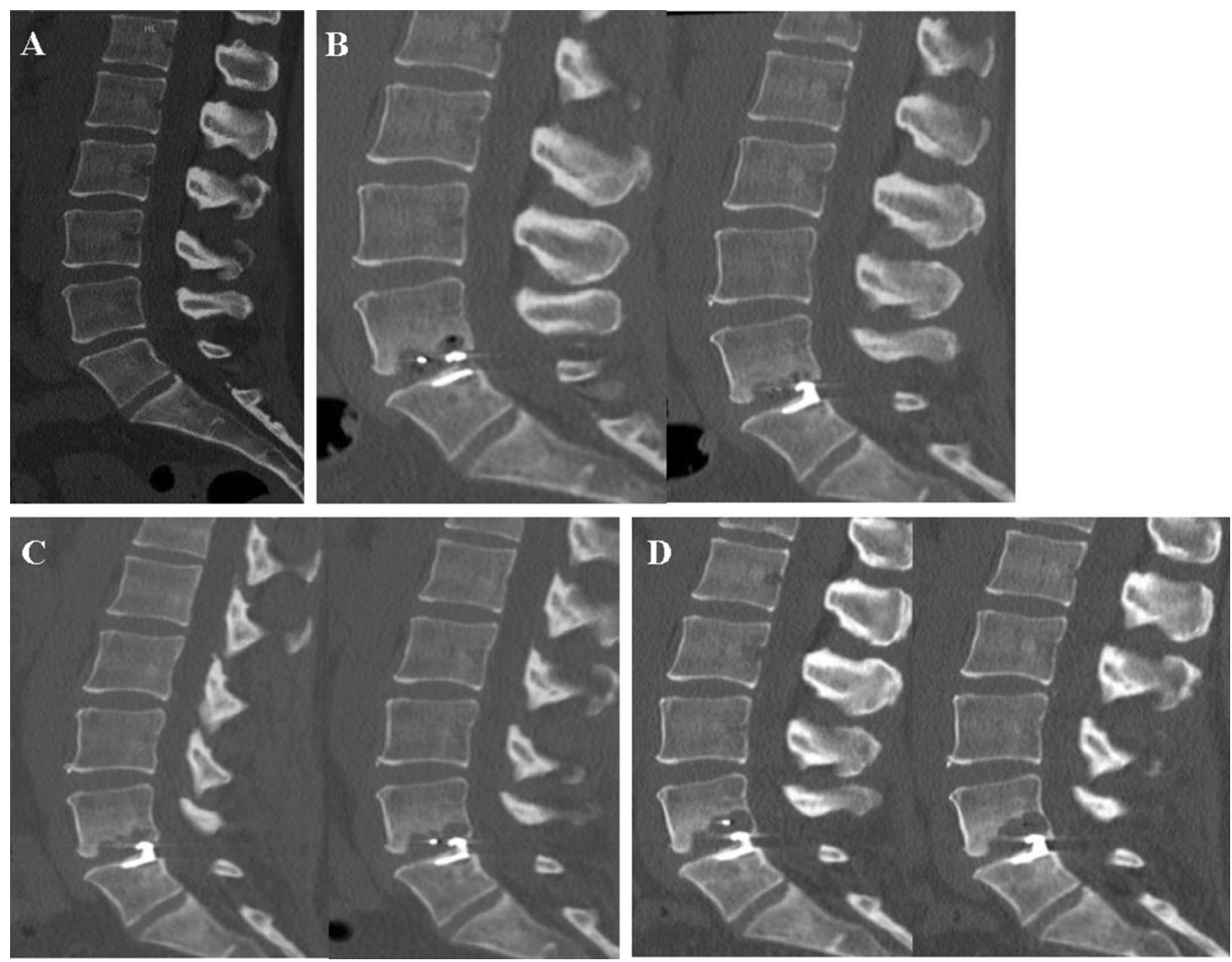

Fig. 5 Case report of a patient that underwent $L M D$ and $A C D$ implantation at $L 4 / 5$ level due to disc herniation. a Preoperative baseline $C T$ : No EPC visible. b One-year follow-up: EPC $\left(0.57 \mathrm{~cm}^{3}\right)$ appear at the lower EP of L4. c 2-year follow-up: EPC $\left(1.15 \mathrm{~cm}^{3}\right)$ progressed at lower EP of L4. $\mathbf{d} 3$-year follow-up: EPC $\left(2.46 \mathrm{~cm}^{3}\right)$ accelerated to a grade 3, with polymer mesh subsidence into lower EP of L4

the whole implant $(\mathrm{n}=4)$, or only the polymer mesh $(\mathrm{n}=3)$ had been removed. A total of $17(24 \%)$ patients revealed reherniation in the postoperative followup MRI, 10 patients (13.8\%) were symptomatic and 7 $(10 \%)$ asymptomatic. In addition to conservative treatments $(n=4)$, reoperation was necessary in $6(8.3 \%)$ patients in the symptomatic cohort. The procedures included recurrent LMD only $(\mathrm{n}=3)$, LMD with ACD removal $(\mathrm{n}=1)$ and LMD with mesh removal $(\mathrm{n}=2)$. A device failure occurred in 19 (26.4\%) patients. "Failure" was defined as: dislocation of the whole device $>2 \mathrm{~mm}$ $(\mathrm{n}=5,6.9 \%)$, device anchor-head breakage $(\mathrm{n}=1$, $1.3 \%)$, or posterior dislocation of the mesh into spinal canal $(\mathrm{n}=13,18 \%)$. Mesh subsidence into EPC was documented in 15 (20.8\%) patients (Table 5 and Fig. 6). Overall, 7 patients (9.7\%) underwent reoperation due to device failure within the follow-up period. In terms of reoperation techniques, the following surgical approaches were used in a total of 13 reoperations (18.1\%): Re-LMD only $(\mathrm{n}=3,4 \%)$, removal of polymer mesh and LMD $(n=2,3 \%)$, LMD with mesh and anchor-head removal $(\mathrm{n}=1,1 \%)$, explant of the whole ACD and LMD $(n=1,1 \%)$, transpedicular fusion with

\section{Table 5 Types of surgical and device failure}

\begin{tabular}{ll}
\hline Type of surgical and device failure & $\mathbf{n}(\%)$ \\
\hline Dislocation of whole ACD & $5(6.9)$ \\
ACD anchor head breakage & $1(1.3)$ \\
Posterior dislocation of mesh into spinal canal & $13(18)$ \\
Mesh subsidence into endplate & $15(20.8)$ \\
Symptomatic reherniation & $10(13.8)$ \\
Reoperation due to recurrent herniation & $6(8.3)$ \\
Reoperation due to device failure & $7(9.7)$ \\
\hline
\end{tabular}

ACD in place $(\mathrm{n}=3,4 \%)$ and fusion with ACD removal $(\mathrm{n}=3,4 \%)$ (Table 6). All reoperations occurred on average $18 \pm 11$ months after LMD and ACD implantation. According to the surgeons, reoperation and $A C D$ removal was more difficult than re-LMD only. An unintended durotomy during reoperation occurred in 31\% of cases. During all revision surgeries, portions of the mesh, bone and disc material were sent for bacteriological growth testing, and any ongoing infection was excluded. 


\section{Clinical outcome}

In summary, the surgery achieved significant improvements with good clinical outcome. These findings are most likely independent from the ACD implantation and a normal consequence of LMD surgery. Mean preoperative ODI of 57.27 decreased significantly postoperative to a mean of 17.58 (95\% CI [35.71, 46.99] p <0.001). With regard to low back pain VAS, a preoperative mean of 63.53 showed significant postoperative reduction to $19.80(95 \% \mathrm{CI}[35.32,57.26] \mathrm{p}<0.001)$. Left leg pain VAS, decreased significant from a mean of 45.66 preoperative to 11.46 postoperative (95\% CI [23.72, 49.26] $\mathrm{p}<0.001)$. Similarly, right leg pain VAS reduced from a preoperative mean of 42.97 to postoperative 10.79 (95\% CI $[21.45,49.72] \mathrm{p}<0.001$ ) (Fig. 7). We also investigated if the magnitude of EPC had any influence on postoperative outcome. In particular, lower EPC showed significant correlation with postoperative ODI at the last follow-up only $(\mathrm{p}=0.01)$ and a trend was present with lower EPC and last postoperative low back pain VAS $(\mathrm{p}=0.6)$. In fact, EPC do not seem to affect postoperative clinical outcome in a significant manner.

\section{Disc degeneration}

MRI findings prior and after surgery were compared with a mean postoperative follow-up of $22.7 \pm 9.7$ months to assess DDD. Preoperative mean disc height measured $6.2 \pm 1 \mathrm{~mm}$ and decreased postoperatively to a mean of $5.5 \mathrm{~mm} \pm 1 \mathrm{~mm}$. This $0.7 \pm 0.6 \mathrm{~mm}$ reduction in disc height was non-significant. Disc degeneration at index level was Pfirrmann grade III in $49 \%$ preoperative and $66 \%$ postoperative (Fig. 8 ). A third of patients (31\%) had no Modic changes before surgery, and Type 1 increased from 14 to $44 \%$ (Fig. 9).

\section{Discussion}

The findings of this study support nascent evidence that ACD implantation after LMD might accelerate EPC and lead to osteolysis of the surrounding bone. In this study, EPC was documented in almost all patients during follow-up. Nevertheless, no impact on clinical outcome was apparent.

The present study revealed a reherniation rate of $14 \%$, which is in the $3 \%-18 \%$ range following LMD reported in the literature [2]. The 3 year follow-up results from the multicenter randomized controlled European trial (RCT LMD-ACD), comparing LMD and ACD versus LMD only showed a symptomatic reherniation rate of $14.8 \%$ in the ACD group, versus $29.5 \%$ in the control group [12].

Our reoperation rate of $18 \%$ during the 18 -months postoperative period was above reported average between 1 and 11.5\% [1, 26]. In comparison, the RCT LMD-ACD trial showed that index level reoperations were significantly less frequent with ACD (9\% vs. $16 \%$ after 2 years and $11 \%$ vs. $19.3 \%$ after 3 years) [12, 23].

Other studies have also reported the appearance of EPC after LMD and ACD [14]. One case report described ACD removal and fusion 1.5 months after surgery due to resorbed bone in vicinity of the device and inflammatory changes in the adjacent tissue [13]. In the RCT LMD - ACD study, EPC were significantly more prevalent in the ACD group compared to the control group ( $84 \%$ vs. $30 \%$ after 2 years and $89 \%$ vs. $41 \%$ after 3 years) $[12,23]$. At baseline, the number of patients showing EPC was similar in both groups [5]. The number and total EPC volume increased more significantly in the ACD group over time [5]. Barth et al. had reported earlier that ACD implantation in the superior EP causes more frequent and larger EPC in the opposite lower EP due to applied pressure from the mesh [5]. Indeed, the lower endplate seems to be more affected by DDD and ongoing tissue damage. [3].

Endplate changes themselves are a common finding after LMD only, with a reported incidence of $43 \%-57 \%$ $[4,25]$. There might be an association in LMD between surgical technique and aggressive treatment of sensitive EP. Earlier studies have shown, that endplate changes and DDD are related $[8,21]$. In the present study, no relevant increase of DDD grade was seen during follow up.

In cases with $\mathrm{ACD}$, the flexible polymer mesh might cause friction, leading to EPC around the mesh. More research and improvement of implant design is needed. Although anatomy mainly determines the anchor position, in general, ACD implantation in the superior EP should be avoided.

Lange et al. recently reported on a symptomatic ACD loosening due to infection with Propionibacterium acnes, which they confirmed after revision surgery [15]. In our series, disc material cultures and device

\footnotetext{
(See figure on next page.)

Fig. 6 Several types of device failure are shown. a Dislocation of the whole device posterior into spinal canal. Patient underwent rediscectomy and ACD removal. b Device material failure: fracture of the titanium anchor-head and dislocation toward spinal canal. Rediscectomy and anchor head and mesh removal was performed. c Posterior dislocation of polymer mesh into spinal canal. A LMD and mesh removal was performed during revision surgery. $\mathbf{d}$ Intraoperative picture of removed ACD device. e Radiological appearance of mesh subsidence into EPC and vertebra osteolysis. Clinically asymptomatic finding, no reoperation necessary to-date. $\mathbf{f}$ ACD failure: symptomatic recurrent disc herniation at the index level leading to a reoperation with $L M D$ only
} 

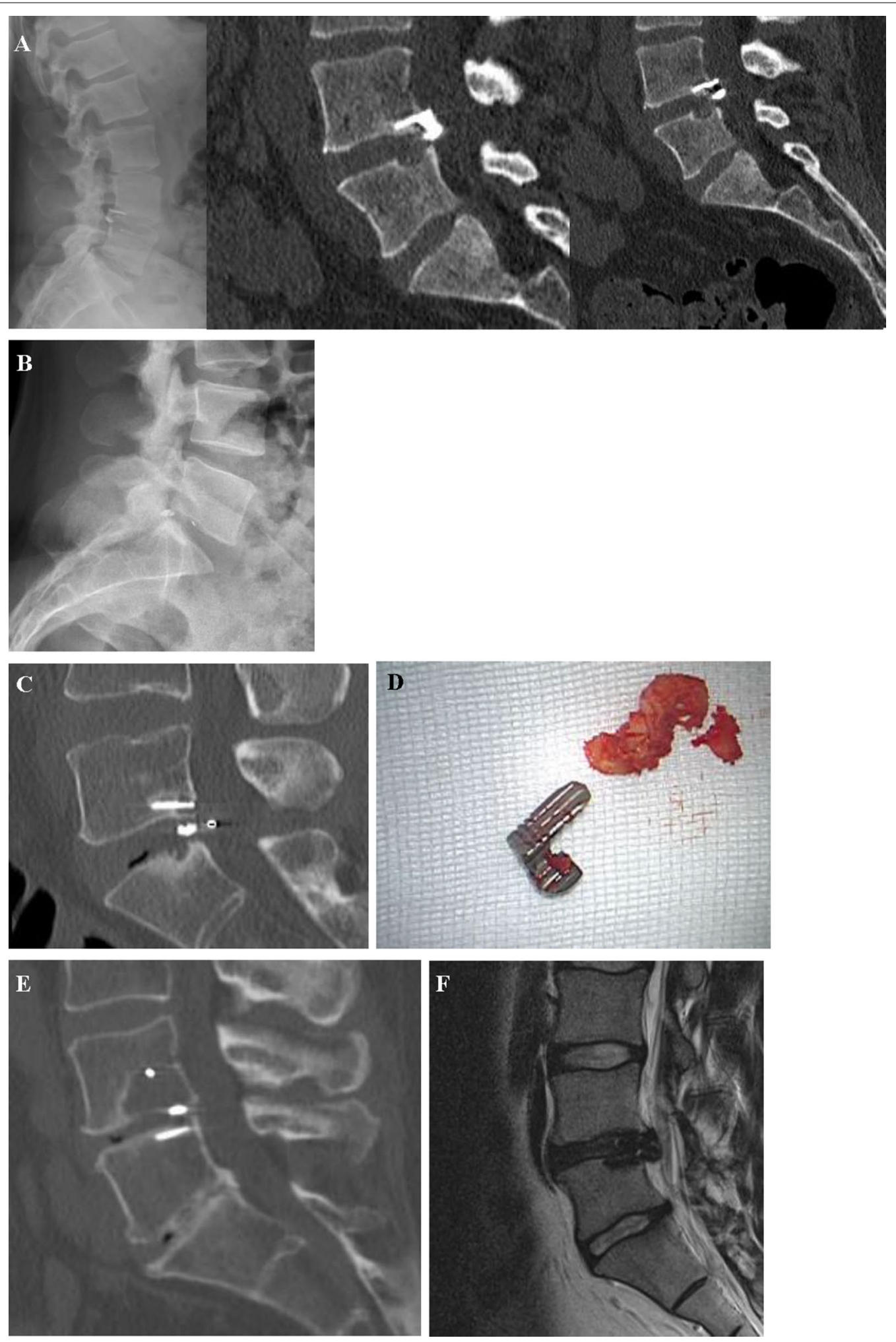
Table 6 The patient subgroup that underwent reoperation due to recurrent disc herniation or device failure. Details of reoperation, implant approach and any complications are presented

\begin{tabular}{|c|c|c|c|c|c|c|}
\hline Patient number & Age & Diagnosis & $\begin{array}{l}\text { Type } \\
\text { of recurrent } \\
\text { surgery }\end{array}$ & $A C D$ procedure & $\begin{array}{l}\text { Time } \\
\text { to reoperation } \\
\text { (months) }\end{array}$ & Complication \\
\hline \multicolumn{7}{|l|}{ Reoperations } \\
\hline 1 & 48 & $\begin{array}{l}\text { Recurrent herniation \& mesh dislocation } \\
\text { SC }\end{array}$ & LMD & Mesh removal & 18 & None \\
\hline 2 & 48 & Instability & Fusion & None & 24 & None \\
\hline 3 & 30 & Anchor head breakage & LMD & Mesh \& anchor head removal & 29 & None \\
\hline 4 & 33 & ACD dislocation & LMD & ACD removal & 17 & Dural injury \\
\hline 5 & 53 & Instability & Fusion & None & 46 & None \\
\hline 6 & 57 & Instability & Fusion & None & 10 & None \\
\hline 7 & 47 & $\begin{array}{l}\text { Recurrent herniation \& mesh dislocation } \\
\text { SC }\end{array}$ & Fusion & ACD removal & 25 & None \\
\hline 8 & 34 & Recurrent herniation & LMD & None & 15 & None \\
\hline 9 & 40 & Recurrent herniation & LMD & None & 8 & None \\
\hline 10 & 33 & Recurrent herniation & LMD & None & 14 & Dural injury \\
\hline 11 & 32 & Instability & Fusion & ACD removal & 7 & CSF leak, revision \\
\hline 12 & 51 & Instability & Fusion & ACD removal & 3 & Dural injury \\
\hline 13 & 31 & $\begin{array}{l}\text { Recurrent herniation \& mesh dislocation } \\
\text { SC }\end{array}$ & LMD & Mesh removal & 20 & None \\
\hline
\end{tabular}

Of note: unintended durotomy occurred in $31 \%$ of reoperations. SC spinal canal

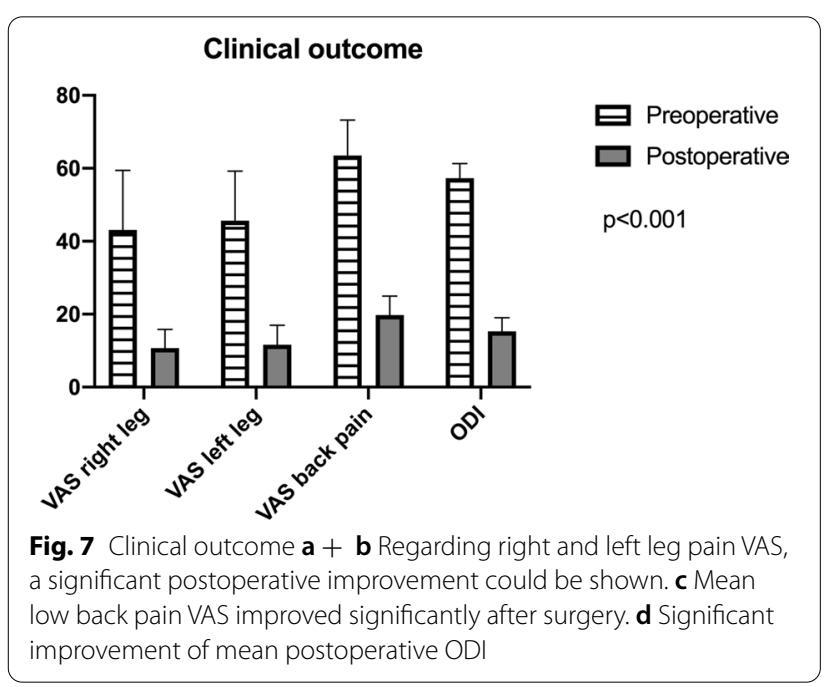

sonification ruled out any low-grade infection as a possible cause of EPC.

A descriptive classification was introduced to facilitate interprofessional communication about ACD-associated EPC. This scoring system was validated in our patient cohort but further external score validation will be necessary.

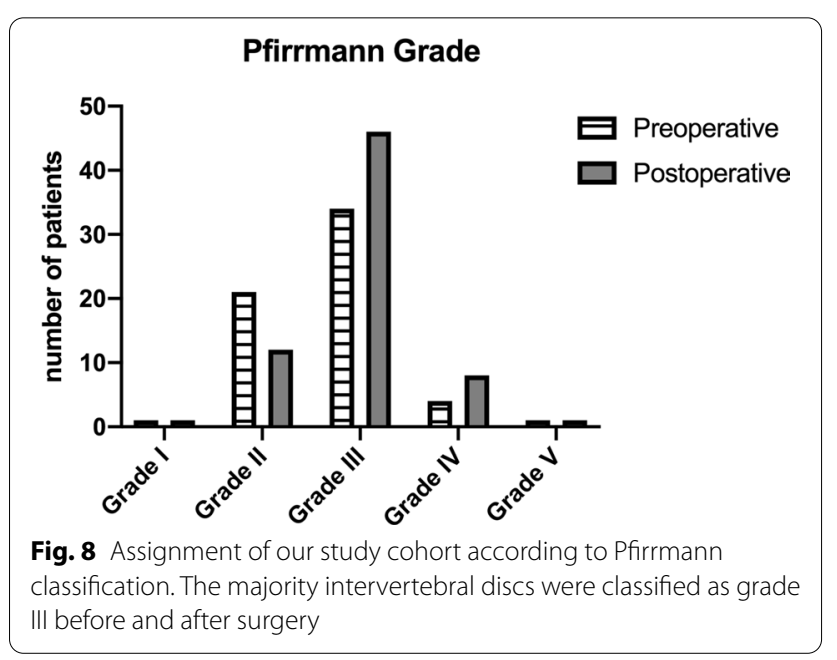

Finally, the risk of EPC must be balanced against a possible lower reherniation rate. Based on our experience, we would suggest that only patients with a large annular defect $(>6 \mathrm{~mm}$ ) and high remaining disc volume should be considered for ACD implantation on the inferior EP. Of higher importance is an improvement of surgical techniques to achieve smaller annular incisions $(<6 \mathrm{~mm})$ in order to prevent reherniation. 


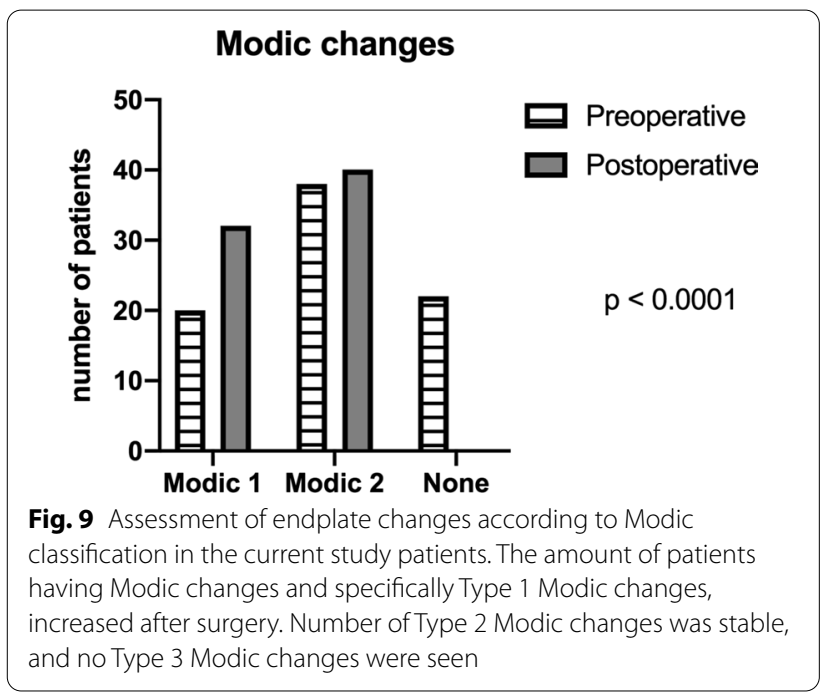

\section{Study limitations}

Limitations of our current study are the fact that this is a non-comparative single center study with a small patient cohort.

\section{Conclusion}

There was significant postoperative clinical improvement after limited LMD and ACD implantation. The high incidence and volume of EPC did not affect clinical outcome. The ACD might prevent disc reherniation despite implant failure rates. Long-term clinical and radiological assessments is necessary to evaluate the consequences of these findings.

\section{Abbreviations}

ACD: Annular Closure Device; CT: Computed Tomography; EPC: Endplate Changes; EP: Endplate; DDD: Degenerative Disc Disease; LMD: Limited Microdiscectomy; MRI: Magnetic Resonance Imaging; ODI: Oswestry Disability Index; RCT: Randomized Controlled Trial; VAS: Visual Analogue Scale.

\section{Acknowledgements}

Not applicable.

\section{Authors' contributions}

JK, SR, SB, HA, and JF designed the study, enrolled patients, and were involved with data acquisition. FB and OW were involved with data acquisition. JK, SR and JK drafted and edited the manuscript. All authors read and approved the final manuscript.

\section{Funding}

No funding was available for this study.

\section{Availability of data and materials}

This study includes data of a post-marketing, prospective, multicenter, randomized controlled trial (RCT) of limited discectomy — with and without use of an annular closure device (Clinicaltrials.gov NCT01283438) undergoing surgical treatment at our Institution. All data generated or analyzed during this study are included in this published article and can be made available from the corresponding author on reasonable request.

\section{Ethics approval and consent to participate}

All procedures performed in studies involving human participants were in accordance with the ethical standards of the institutional and national research committee and with the 1964 Helsinki declaration and its later amendments or comparable ethical standards. The study was approved by the local ethics committee northwestern and central Switzerland (EKNZ) for the multicenter randomized study and for the retrospective data analysis (EKNZ numbers 2012-036; 2016-01740). Written Informed consent was obtained for all patients.

\section{Consent for publication}

Informed consent process included written consent for publication of clinical data and images.

\section{Competing interests}

None of the authors had any conflicts of interest. No disclosures need to be made.

\section{Author details}

${ }^{1}$ Department of Neurosurgery, Kantonsspital Aarau, Tellstrasse, 5001 Aarau, Switzerland. ${ }^{2}$ Department of Health Sciences and Technology, ETH Zurich, Zurich, Switzerland. ${ }^{3}$ Neuro Research Office, Neurocenter, Kantonsspital Aarau, Aarau, Switzerland.

Received: 28 July 2020 Accepted: 14 December 2020

Published online: 06 January 2021

\section{References}

1. Aizawa T, Ozawa H, Kusakabe T, Nakamura T, Sekiguchi A, Takahashi A, Sasaji T, Tokunaga S, Chiba T, Morozumi N, Koizumi Y, Itoi E. Reoperation for recurrent lumbar disc herniation: a study over a 20-year period in a Japanese population. J Orthop Sci. 2012;17:107-13. https://doi. org/10.1007/s00776-011-0184-6.

2. Ambrossi GL, McGirt MJ, Sciubba DM, Witham TF, Wolinsky JP, Gokaslan ZL, Long DM (2009) Recurrent lumbar disc herniation after single-level lumbar discectomy: incidence and health care cost analysis. Neurosurgery 65:574-578 (discussion 578) doi: https://doi.org/10.1227/01. NEU.0000350224.36213.F9

3. Arpinar VE, Rand SD, Klein AP, Maiman DJ, Muftuler LT. Changes in perfusion and diffusion in the endplate regions of degenerating intervertebral discs: a DCE-MRI study. Eur Spine J. 2015;24:2458-67. https://doi. org/10.1007/s00586-015-4172-y.

4. Barth M, Fontana J, Thome C, Bouma GJ, Schmieder K. Occurrence of discal and non-discal changes after sequestrectomy alone versus sequestrectomy and implantation of an anulus closure device. J Clin Neurosci. 2016;34:288-93. https://doi.org/10.1016/j.jocn.2016.09.013.

5. Barth M, Weiss C, Bouma GJ, Bostelmann R, Kursumovic A, Fandino J, Thome C. Endplate changes after lumbar discectomy with and without implantation of an annular closure device. Acta Neurochir. 2018;160:85562. https://doi.org/10.1007/s00701-017-3463-y.

6. Carragee EJ, Han MY, Suen PW, Kim D. Clinical outcomes after lumbar discectomy for sciatica: the effects of fragment type and anular competence. J Bone Joint Surg Am. 2003;85:102-8.

7. Fairbank JC, Pynsent PB. The Oswestry Disability Index. Spine. 2000:25:2940-52 (discussion 2952).

8. Feng Z, Liu Y, Yang G, Battie MC, Wang Y. Lumbar vertebral endplate defects on magnetic resonance images: classification, distribution patterns, and associations with modic changes and disc degeneration. Spine. 2018;43:919-27. https://doi.org/10.1097/BRS.0000000000002450.

9. Fritzell P, Knutsson B, Sanden B, Stromqvist B, Hagg O. Recurrent versus primary lumbar disc herniation surgery: patient-reported outcomes in the swedish spine register swespine. Clin Orthop Relat Res. 2015;473:1978-84. https://doi.org/10.1007/s11999-014-3596-8.

10. Hawker GA, Mian S, Kendzerska T, French M. Measures of adult pain: Visual Analog Scale for Pain (VAS Pain), Numeric Rating Scale for Pain (NRS Pain), McGill Pain Questionnaire (MPQ), Short-Form McGill Pain Questionnaire (SF-MPQ), Chronic Pain Grade Scale (CPGS), Short Form-36 Bodily Pain Scale (SF-36 BPS), and Measure of Intermittent and Constant 
Osteoarthritis Pain (ICOAP). Arthritis Care Res. 2011;63(Suppl 11):S240252. https://doi.org/10.1002/acr.20543.

11. Kienzler J, Rey S, Wetzel O, Atassi H, Bäbler S, Fandino J. Incidence and Clinical Impact of Vertebral Endplate Changes after Limited Lumbar Microdiscectomy and Implantation of a Bone-anchored Annular Closure Device. San Diego, CA, USA: Paper presented at the AANS Annual Meeting; 2019.

12. Kienzler JC, Klassen PD, Miller LE, Assaker R, Heidecke V, Frohlich S, Thome C, Annular Closure RCTSG. Three-year results from a randomized trial of lumbar discectomy with annulus fibrosus occlusion in patients at high risk for reherniation. Acta Neurochir. 2019;161:1389-96. https://doi. org/10.1007/s00701-019-03948-8.

13. Krutko AV, Baykov ES, Sadovoy MA. Reoperation after microdiscectomy of lumbar herniation: Case report. Int J Surg Case Rep. 2016;24:119-23. https ://doi.org/10.1016/j.ijscr.2016.04.043.

14. Kursumovic A, Kienzler JC, Bouma GJ, Bostelmann R, Heggeness M, Thome C, Miller LE, Barth M, Closure A, RCTsg, . Morphology and clinical relevance of vertebral endplate changes following limited lumbar discectomy with or without bone-anchored annular closure. Spine. 2018. https ://doi.org/10.1097/BRS.0000000000002632.

15. Lange N, Meyer B, Shiban E. Low-grade infection due to annular closure device. Acta Neurochir. 2018;160:1867. https://doi.org/10.1007/s0070 1-018-3611-z.

16. McGirt MJ, Ambrossi GL, Datoo G, Sciubba DM, Witham TF, Wolinsky JP, Gokaslan ZL, Bydon A. Recurrent disc herniation and long-term back pain after primary lumbar discectomy: review of outcomes reported for limited versus aggressive disc removal. Neurosurgery. 2009;64:338-44. https ://doi.org/10.1227/01.NEU.0000337574.58662.E2 (discussion 344-335).

17. Modic MT, Steinberg PM, Ross JS, MasarykTJ, Carter JR. Degenerative disk disease: assessment of changes in vertebral body marrow with MR imaging. Radiology. 1988;166:193-9. https://doi.org/10.1148/radio logy.166.1.3336678.

18. MrozTE, Lubelski D, Williams SK, O'Rourke C, Obuchowski NA, Wang JC, Steinmetz MP, Melillo AJ, Benzel EC, Modic MT, Quencer RM. Differences in the surgical treatment of recurrent lumbar disc herniation among spine surgeons in the United States. Spine J. 2014;14:2334-43. https://doi. org/10.1016/j.spinee.2014.01.037.

19. Parker SL, Grahovac G, Vukas D, Vilendecic M, Ledic D, McGirt MJ, Carragee EJ. Effect of an Annular Closure Device (Barricaid) on Same-Level Recurrent Disk Herniation and Disk Height Loss After Primary Lumbar
Discectomy: Two-year Results of a Multicenter Prospective Cohort Study. Clin Spine Surg. 2016;29:454-60. https://doi.org/10.1097/BSD.0b013 e3182956ec5.

20. Pfirrmann CW, Metzdorf A, Zanetti M, Hodler J, Boos N. Magnetic resonance classification of lumbar intervertebral disc degeneration. Spine. 2001;26:1873-8.

21. Rade M, Maatta JH, Freidin MB, Airaksinen O, Karppinen J, Williams FMK. Vertebral endplate defect as initiating factor in intervertebral disc degeneration: strong association between endplate defect and disc degeneration in the general population. Spine. 2018;43:412-9. https:// doi.org/10.1097/BRS.0000000000002352.

22. Spengler DM. Lumbar discectomy. Results with limited disc excision and selective foraminotomy. Spine. 1982;7:604-7.

23. Thome C, Klassen PD, Bouma GJ, Kursumovic A, Fandino J, Barth M, Arts $M$, van den Brink W, Bostelmann R, Hegewald A, Heidecke V, Vajkoczy P, Frohlich S, Wolfs J, Assaker R, Van de Kelft E, Kohler HP, Jadik S, Eustacchio $\mathrm{S}$, Hes R, Martens F, Annular Closure RCTSG. Annular closure in lumbar microdiscectomy for prevention of reherniation: a randomized clinical trial. Spine J. 2018. https://doi.org/10.1016/j.spinee.2018.05.003.

24. Watters WC 3rd, McGirt MJ. An evidence-based review of the literature on the consequences of conservative versus aggressive discectomy for the treatment of primary disc herniation with radiculopathy. Spine J. 2009;9:240-57. https://doi.org/10.1016/j.spinee.2008.08.005.

25. Weiner BK, Vilendecic M, Ledic D, Eustacchio S, Varga P, Gorensek M, Fernandez-Moure J, Hipp JA. Endplate changes following discectomy: natural history and associations between imaging and clinical data. Eur Spine J. 2015;24:2449-57. https://doi.org/10.1007/s00586-014-3734-8.

26. Yoshihara H, Chatterjee D, Paulino CB, Errico TJ. Revision Surgery for "Real" recurrent lumbar disk herniation: a systematic review. Clin Spine Surg. 2016;29:111-8. https://doi.org/10.1097/BSD.0000000000000365.

\section{Publisher's Note}

Springer Nature remains neutral with regard to jurisdictional claims in published maps and institutional affiliations.
Ready to submit your research? Choose BMC and benefit from:

- fast, convenient online submission

- thorough peer review by experienced researchers in your field

- rapid publication on acceptance

- support for research data, including large and complex data types

- gold Open Access which fosters wider collaboration and increased citations

- maximum visibility for your research: over $100 \mathrm{M}$ website views per year

At BMC, research is always in progress.

Learn more biomedcentral.com/submissions 